\title{
Is NY's Supply-Side Experiment Working? A Preliminary Analysis using County Unemployment Rates
}

\author{
LYNN B. SNARR \\ Westminster College \\ HAL SNARR* \\ Westminster College \\ DAN FRIESNER \\ North Dakota State University
}

\begin{abstract}
The State of New York recently enacted business tax reforms. The first legislative act launched the START-UP NY program in 2014. It created tax free enterprise zones throughout the state to incentivize business incubation within, or relocation of existing firms to, the State of New York. In that same year, the state lowered its corporate tax rate state-wide from $7.1 \%$ to $6.5 \%$ in 2016 . We use a difference-in-differences (DID) methodology, evaluated using county-level data, to empirically test whether New York's recent business tax reforms significantly reduce unemployment, beyond what would exist in the absence of the reforms. We fail to find significant evidence that START-UP NY affects unemployment during the period studied, 2014-2017. We do, however, find evidence suggesting that New York lowering its corporate tax rates in 2016 is associated with a reduction in unemployment (by approximately 90,000 jobs) in 2016 and a smaller reduction (by approximately 25,000 jobs) in 2017 .
\end{abstract}

Keywords: entrepreneurship, employment, regional economic development

JEL Classifications: J38, Q23, R14

\section{Introduction and Literature Review}

The ultimate goal of entrepreneurship is to initiate and grow an economic organization (Rocha, 2004). Growth can be characterized in a variety of ways, including sales, profitability, employment and market share. Economic development policies that encourage entrepreneurship may, at the level of the firm, be measured through the overall contribution of entrepreneurial activities to the local economy. A sufficient, comprehensive measure to

\footnotetext{
*Corresponding author; hsnarr@westminstercollege.edu

(C) 201? Author's Name (names); . Licensed under the Creative Commons Attribution Noncommercial 3.0 Licence (http://creativecommons.org/licenses/by-nc/3.0/. Available at http: //rofea.org.
} 
assess the impact of entrepreneurial activities is the change in employment (or unemployment) within the local economy (Thurik and Wennekers, 2004). Firms that employ more workers likely generate greater sales and/or profit than other comparable firms with fewer employees. Since a larger, local employment base spends much of its income in the local community, the indirect and induced effects of greater firm employment are likely higher as well. Perhaps more importantly, individuals living in those communities experience greater quality of life and enhanced opportunities to better themselves in a variety of ways (greater education, enhanced social and political capital, etc.) beyond having a higher standard of living (Rocha, 2004).

The State of New York launched the SUNY Tax-free Areas to Revitalize and Transform UPstate NY, or START-UP NY, to attract and retain businesses. The program denoted a dramatic shift in the state's approach to economic development. It began providing financial incentives to promote local entrepreneurial endeavors in enterprise zones that are on or near public universities (Bruns, 2013; Gormley, 2015). The location of these zones are shown in Figure 1.

Figure 1: START-UP NY and Non-START-UP NY Counties

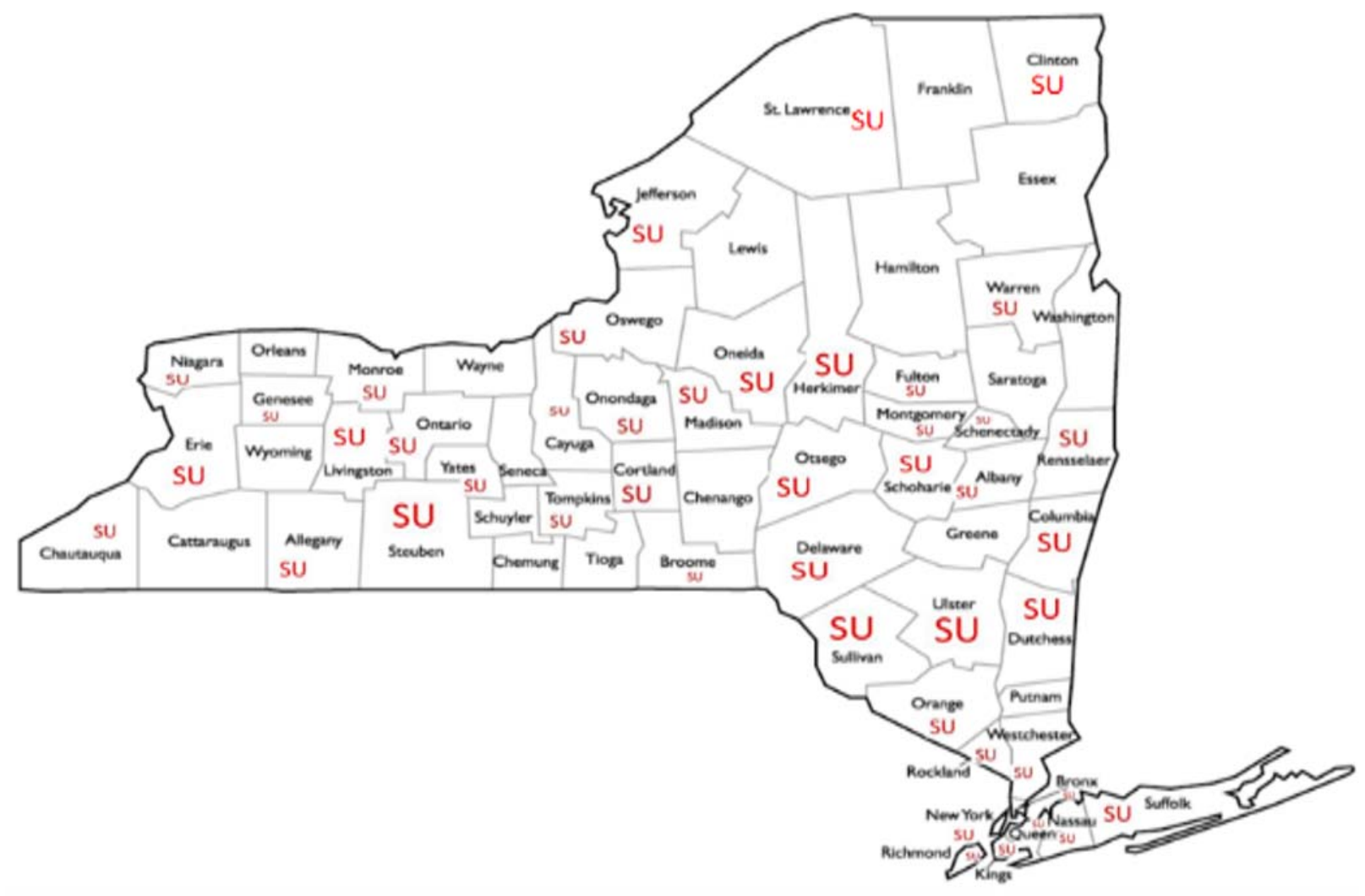




\section{SNARR, SNARR, FRIESNER New York Supply-Side Experiment}

For businesses with $100 \%$ of their operations in these zones, all business taxes at the state or local level are refunded every year (for a ten-year period) via annual tax credits that are determined when firms file annual tax returns. Personal income, Metropolitan Commuter Transportation District mobility, sales, and property may also be exempt from taxes for 10 years. For firms that operate partially in tax-free zones, the tax credits are pro-rated based on the percentage of assets and payroll within the tax-free zone(s). Retailers, hotels, medical providers, law offices, and others are not allowed to participate in the program.

In practice, START-UP NY, according to Chumley (2014), contains a very convoluted set of regulations and exceptions that may limit its effectiveness. For example, although the program promises that "employees will pay no state or local personal income taxes" (Chumley, 2014), all positions qualifying for this tax exemption must be approved by the program's administrators. Once approved, the tax benefit may not be fully realized. After the fifth year of a firm's participation in the program, for example, an employee must pay taxes on annual income over $\$ 200,000$ (Chumley, 2014). There are also limits to the number of workers at each firm who are eligible for tax-free pay.

During the year that START-UP NY was launched, the State of New York also passed legislation that lowered its corporate tax rate from $7.1 \%$ to $6.5 \%$ in 2016 and beyond (Henchman, 2014, Table 2). Thus, the business tax reforms zeroed tax rates for some firms in START-UP NY counties but reduced the tax rates for all businesses throughout the state. The reforms are a simple application of supply-side economics where lower tax rates reduce firms' production costs, which leads to greater supply of products and services, which, in turn, leads to a greater gross state product (GSP). Higher GSP means more employment opportunities for and reduced unemployment among New York residents.

Whether the aforementioned regulatory details completely or partially mitigate the incentive to start or relocate businesses in tax-free zones, which was the case for a similar program in Alabama (Couch and Barrett, 2004), the effectiveness of START-UP NY and the state-wide corporate tax rate reductions are fundamentally empirical issues. However, given that the two reforms were launched together, it is paramount that any econometric analyses of these issues disentangle the effects of these two reforms. To our knowledge, this is the first paper that empirically evaluates the effectiveness of tax-free enterprise zones and a coincident reduction in corporate tax rates. There are several studies that investigated the effects of the enterprise zones that had been launched in 30 states during the late eighties (Erickson and Friedman, 1989). They found that economic performance (e.g., job growth or return on investment) in enterprise zones outperformed national trends (Erickson and Friedman, 1989; Rubin and Wilder, 1989; Bennett, 1990; Erickson and Friedman, 1990; Couch and Barrett, 2004; Couch, Atkinson, and Smith, 2005). More generally, Rubin and Boyd (2013) used over 60 years of data to analyze the impact of business tax incentives on state-level economic growth. This study found no evidence suggesting that tax incentives contribute to economic 
growth, over and above normal growth that would have occurred had the tax incentives never been implemented.

There is also related research that looks at the effects of tax credits on research and development. Wilson (2009), studying the effects of R\&D tax credits on firms' investments in $R \& D$, found that such credits shifted firm $R \& D$ spending from states that did not provide them to states that did. According to Erickson and Friedman (1990), this is not the case for enterprise zones. Czarnitzki, Hanel, and Rosa (2011) found that because small-to-medium sized firms are not aware of the tax credits, and they use financial capital for equipment first and innovation second, tax credits lower the cost of R\&D that large firms would have done otherwise.

The purpose of this paper is to empirically examine changes in county-level unemployment rates to disentangle the effects of New York States recent supply-side tax reforms. The rest of the paper is organized as follows. In the next section, we develop a difference-in-differences (DID) econometric model, based on the unique natural experimental features of the New York tax reforms, to estimate the changes in unemployment attributable to these changes. The third section discusses the data and their sources used to estimate the econometric model. The fourth section presents and discusses the empirical results. The final section concludes the manuscript and suggests some opportunities for future research.

\section{Empirical Methodology}

Since New York State's business tax reforms are relatively new, a comprehensive set of data (including multiple measures of program outcomes tracked over time) to empirically assess its effectiveness is limited. Hence, this paper adopts a conservative, systematic approach and focuses on an outcome measure (the unemployment rate) that explicitly and implicitly captures intended program effects and is available over multiple years at a disaggregated (county) level. We operate under the null hypothesis of no significant relationship between county unemployment rates and the changes to New York State's business tax policy. The analysis also adopts a stepwise development of its econometric methodology. It initially considers a simple empirical formulation, and subsequently adds complexity (based on the applied econometric and policy evaluation literatures) to address potentially confounding factors that may bias simpler econometric models. By estimating the final, more complex econometric models, it is possible to more comprehensively disentangle the competing effects of other economic policies and various factors that influence the local economy coincident to the implementation of START-UP NY and the coincident reduction in the state's corporate tax rate.

The unemployment rate in each county (urate) serves as the dependent variable. We assess changes in unemployment rates that are associated with the implementation of New York's 2014 tax reforms in New York counties relative to their Pennsylvania counterparts. As 
such, our methodology can be considered as a natural experimental design, with test and control groups (Wooldridge, 2000; 414-419). The New York county binary variable (NY) assigns a value of one to New York counties and a value of 0 to Pennsylvania counties. Since New York adopted business tax reforms and Pennsylvania did not, residents of New York counties are in the treatment group and residents of Pennsylvania are in the control group.

Card and Krueger's (1994) DID methodology is used to empirically assess employment differences between test and control groups. ${ }^{1}$ This methodology assumes the existence of a two-period panel of data (randomly drawn without bias from a well-defined population) that can appropriately be treated as a pooled cross-section. Consistent with a natural experiment, at least one of these time periods should occur sufficiently later than the policy intervention to measure outcomes arising from the intervention.

A potentially confounding factor in economic development is that a lag typically exists between the implementation of economic development incentives and the use of those incentives by entrepreneurs. To account for this lag, a second binary variable, YEAR, indicates whether an observation that was collected after the implementation of the New York State's business tax reforms, both of which occurred in $2014 .^{2}$ For example, if data are collected in 2014 and 2015, YEAR equals 1 for data collected in 2015, and 0 for the year 2014. Denoting counties with the subscript $i$ and the year of interest with the subscript $t$, the basic Card and Krueger (1994) DID model can be expressed as:

$$
\text { urate }_{i t}=\beta_{0}+\beta_{1} \mathrm{NY}_{\mathrm{i}}+\beta_{2} \mathrm{YEAR}_{\mathrm{t}}+\beta_{3}\left(\mathrm{NY}_{\mathrm{i}} \times \mathrm{YEAR}_{\mathrm{t}}\right)+\varepsilon_{\mathrm{it}}
$$

where $\beta_{0}-\beta_{3}$ are parameters to be estimated, $\beta_{3}$ is the DID estimator, and $\varepsilon$ is a white noise error term with the usual assumptions. As long as the error term in (1) meets all relevant classical statistical assumptions, equation (1) can be estimated using ordinary least squares (OLS). Because equation (1) excludes important county-level information, it is typically augmented by including a series of $\mathrm{k}=1, \ldots, \mathrm{K}$ control variables $(\mathrm{X})$ :

\footnotetext{
${ }^{1}$ While a differences-in-differences methodology is perhaps the most popular means to evaluate natural experiments of this nature, it is not without its limitations. See Duflo, Mullainathan, and Bertrand (2004) for more discussion.

${ }^{2}$ As long as the methodology appropriately accounts for the lag, its existence supports the viability of appropriately employing a DID model (Card and Krueger, 1994; Duflo, Mullainathan, and Bertrand, 2004; Columbia University Mailman School of Public Health, 2018). More specifically, firms cannot receive benefits from either the START-UP NY or the tax reform policies in advance of their implementation. Rather, firms only receive benefits for the time frame following the implementation of the policy, which reduces the incentive to establish startup firms specifically in anticipation of the STARTUP NY program. This also supports (but does not prove) that the policy intervention is not related to county level unemployment rates in the baseline year - a crucial assumption underlying the DID methodology.
} 
Review of Economic Analysis 10 (2018) 245-266

$$
\text { urate }_{i t}=\delta_{0}+\delta_{1} \mathrm{NY}_{\mathrm{i}}+\delta_{2} \mathrm{YEAR}_{\mathrm{t}}+\delta_{3}\left(\mathrm{NY}_{\mathrm{i}} \times \mathrm{YEAR}_{\mathrm{t}}\right)+\sum_{k=1}^{K} \delta_{k+3} X_{i t}^{k}+\xi_{\mathrm{it}}
$$

where $\delta_{0}-\delta_{\mathrm{K}}$ are parameters to be estimated, $\delta_{3}$ is the DID estimator, $\xi$ is a white noise error term with the usual assumptions, and the remaining symbols and variables are as defined previously. Consistent with the previous model, as long as the error term meets all relevant classical assumptions, equation (2) can also be estimated via OLS.

A potential drawback to equation (2) is that the $N Y$ variable is a single dummy variable, with all control counties included in the omitted condition (i.e., a value of zero). This presumes that all counties in the control group are sufficiently similar to be aggregated together, which may or may not be appropriate. As a result, we extend equation (2) to allow for county-level fixed and/or random effects:

urate $_{i t}=\mu_{0}+\mu_{1} \mathrm{NY}_{\mathrm{i}}+\mu_{2} \mathrm{YEAR}_{\mathrm{t}}+\mu_{3}\left(\mathrm{NY}_{\mathrm{i}} \times \mathrm{YEAR}_{\mathrm{t}}\right)+\sum_{l=1}^{L} \mu_{l+3} X_{i t}^{l}+\mathrm{v}_{\mathrm{i}}+\omega_{\mathrm{it}}$

where $\mu_{0}-\mu_{\mathrm{L}}$ are parameters to be estimated (over $1=1, \ldots, \mathrm{L}$ control variables), $\mu_{3}$ is the DID estimator, $\omega$ is a white noise error term with the usual assumptions, $v$ is a county-specific effect for each county i (note that, in certain situations, one county effect may be dropped to prevent multicollinearity), and the remaining symbols and variables are as defined previously.

Another potentially confounding effect is that, once entrepreneurs receive economic development incentives, the speed with which entrepreneurs can grow their businesses and employ new workers (thereby reducing unemployment) may vary from firm to firm. Some firms may parlay incentives into immediate employment growth; we call this the "initialeffect" model. Other firms may require a period of incubation before employment growth is realized. ${ }^{3}$ We call these subsequent models the "intermediate-effect" model and the "tertiaryeffect" model, respectively. Using data from 2014 and 2015 would estimate the employment effects of New York State's business tax reforms in the year they were implemented. Here, YEAR is coded as discussed previously. The intermediate-effects and tertiary-effects could be estimated using data from 2015 and 2016, and from 2016 and 2017, respectively. We note that YEAR would equal 0 in the first year of these models (2015 in the intermediate-effect model and 2016 in the tertiary-effect model) but equal 1 in the second year (2016 in the intermediate-effect model and 2017 in the tertiary-effect model). Complicating these potential confounding effects is that entrepreneurs (within a county, the unit of analysis) may take advantage of the START-UP NY program at its outset, or may not initiate firm incubation until a subsequent year in the panel. In such cases, using only two years of data to estimate initial, intermediate, and tertiary effects may over or under-state the true effectiveness of the

\footnotetext{
${ }^{3}$ As illustrative examples, it may take time for new firms to fully commercialize (i.e., develop and implement new manufacturing processes) for a new technology, to fully develop its supply chains, and to train new employees, among a host of other factors.
} 


\section{SNARR, SNARR, FRIESNER New York Supply-Side Experiment}

policy. ${ }^{4}$ To account for these issues, we estimate a four-period version of the model with 2014 serving as the base case, and separate YEAR binary variables for 2015, 2016, and 2017, respectively:

urate $_{i t}=\alpha_{0}+\alpha_{1} \mathrm{NY}_{\mathrm{i}}+\sum_{j=1}^{J} \alpha_{j+1} Y E A R_{t}^{j}+\sum_{j}^{J} \theta_{j+1}\left(N Y_{i} \times Y E A R_{t}^{j}\right)+\sum_{l=1}^{L} \pi_{l} X_{i t}^{l}+\Delta_{\mathrm{i}}+\Omega_{\mathrm{it}}$

where the $\alpha \mathrm{s}, \theta \mathrm{s}$, and $\pi \mathrm{s}$ are parameters to be estimated, the $\theta \mathrm{s}$ are the DID estimators, $\Omega$ is a white noise error term with the usual assumptions, $\Delta$ is a county-specific effect for each county i (note that, in certain situations, one county effect may be dropped to prevent multicollinearity), and the remaining symbols and variables are as defined previously. While slightly different from Card and Krueger's (1994) original specification, the four-period model allows for a simultaneous assessment of the initial-, intermediate-, and tertiary-effects of New York State's business tax reforms.

A final consideration is that Pennsylvania counties may be fundamentally distinct from counties in New York. Non-comparability across test and control groups violates the DID methodology because, in the absence of the START-UP NY program (and holding other important specified regressors constant), differences in county level unemployment rates would not be constant over time. That is, the common trend assumption is violated (Card and Krueger, 1994; Duflo, Mullainathan, and Bertrand, 2004; Columbia University Mailman School of Public Health, 2018). ${ }^{5}$ This is a primary reason that it is vital to adjust the DID methodology for the corporate tax rate reforms implemented in New York. The use of a shorter time frame (but greater than two years in length) also reduces the likelihood that confounding effects not specified in the regression lead to non-comparability of the test and control groups over time, which also violates the common trend assumption. In general, the only conclusive means to verify the appropriateness of the common trend assumption is to fail to reject our null hypothesis of no relationship between the implementation of START-UP NY and county level unemployment rates (i.e., the policy was inherently ineffective).

Absent this finding, several measures can be taken to increase the likelihood that the common trend assumption holds. One is to provide evidence-based rationale supporting the comparability of the test and control groups. Card and Krueger's (1994) study (which examined the effect of a New Jersey minimum wage increase on New Jersey fast food store

\footnotetext{
${ }^{4}$ As will be discussed shortly, a four year panel strikes a reasonable balance between providing a full set of initial, intermediate, and tertiary effect estimates, and providing a sufficiently small time series to assume that the common trend assumption underlying the DID methodology holds (Columbia University Mailman School of Public Health, 2018). A full set of results of estimating the initialeffect, intermediate-effect, and tertiary-effect models using only two years of data, and discussed in this manuscript, are available upon request.

${ }^{5}$ We thank an anonymous reviewer for raising this point.
} 
employment) argued that eastern Pennsylvania fast food stores were a valid control group in their DID model because "seasonal patterns of employment are similar in New Jersey and eastern Pennsylvania, as well as across high- and low-wage stores within New Jersey" (p. 773). For this reason, they concluded that their "comparative methodology effectively "differences out" any seasonal employment effects" (p. 773). ${ }^{6}$ Using similar logic, Pennsylvania counties are sufficiently comparable to New York counties to serve as an appropriate control group. Both states have larger metropolitan cities on their eastern borders, and each of these cities are located near three large ports. ${ }^{7}$ Both states also have several other large cities with populations of one-hundred thousand or more. ${ }^{8}$ The states are similar politically with metropolitan centers and cities voting Democratic and rural areas voting Republican. Both sets of counties are in states with high tax burdens, as measured by state and local tax revenue as a percentage of income (Tax Foundation, 2017, Table 2), and burdensome small business regulations (Winegarden, 2015, pp. 11).

A second measure that can be taken is to further adapt the DID regression equation to account for the sources of non-comparability across the test and control groups (Wooldridge, 2000; 414-419). As mentioned previously, START-UP NY was launched in the year New York State voted to lower its corporate tax rate. New York and Pennsylvania counties may be non-comparable because the two policies actually create three different groups, rather than two: New York counties benefitting from both the tax reforms and START-UP NY, New York counties benefitting only from changes to corporate tax rates, and Pennsylvania counties who did not benefit from either of these policies. To disentangle these effects, we introduce two control groups: Pennsylvania counties (who have constant corporate tax rates and no START-UP NY program), New York counties with no START-UP NY campus, but who have reduced corporate tax rates, and New York counties with START-UP NY campuses, who may benefit from both economic development policies. Thus, as a final robustness check, equation (4) is modified to specify two control groups using the aforementioned $N Y$ binary variable and the binary variable $S U$, which assigns a value of one to a New York

\footnotetext{
${ }^{6}$ In an earlier study, Card (1992) used data from the Current Population Survey to estimate the effects an increase in California's minimum wage on low-skilled employment. The author employed similar logic to justify using Arizona, Florida, Georgia, New Mexico, and Dallas-Fort Worth as control groups because the control and treatment groups "had very similar labor force participation rates, employment-population ratios, and unemployment rates in 1987" and had "roughly comparable gender, age, and education distributions" (p. 41).

${ }^{7}$ Philadelphia is near the Ports of Philadelphia, Chester, and Wilmington, whereas New York City is near the ports of New York, Newark, and Perth Amboy, according to the US Bureau of Transportation Statistics (2017).

${ }^{8}$ These cities include Pittsburgh, Allentown and Erie in Pennsylvania and Buffalo, Rochester, Yonkers, Syracuse, and Albany in New York.
} 
county that hosts a START-UP NY enterprise zone and a value of 0 to the New York counties that do not:

$$
\begin{aligned}
\text { urate }_{i t}=\gamma_{0} & +\gamma_{1} N Y_{i}+\gamma_{2} S U_{i}+\sum_{j=1}^{J} \gamma_{j+2} Y E A R_{t}^{j}+\sum_{j}^{J} \phi_{j+1}\left(N Y_{i} \times Y E A R_{t}^{j}\right) \\
& +\sum_{j}^{J} \psi_{j+1}\left(S U_{i} \times Y E A R_{t}^{j}\right)+\sum_{l=1}^{L} \zeta_{l+1} X_{i t}^{l}+\mathrm{D}_{\mathrm{i}}+\Xi_{\mathrm{it}}
\end{aligned}
$$

where the $\gamma \mathrm{s}, \phi \mathrm{s}, \psi \mathrm{s}$, and $\zeta \mathrm{s}$ are parameters to be estimated, $\Xi$ is a white noise error term with the usual assumptions, $\mathrm{D}$ is a county-specific effect for each county $\mathrm{i}$ (note that, in certain situations, one county effect may be dropped to prevent multicollinearity), and the remaining symbols and variables are as defined previously. Under this specification, the original DID estimate - the coefficient of the YEAR-NY interactions - capture the unemployment effects of New York reducing its corporate tax rate in 2016. The additional DID estimate- the coefficient characterizing the interaction between the START-UP NY counties and the year binary variables - measure the employment effects of START-UP NY. To differentiate the pair of DID estimates, we use $\operatorname{DID}_{N Y}$ and DID $_{S U}$.

The primary goal of this paper is to estimate equations (4) and (5) and, in doing so, evaluate the study's null hypothesis. Under this null hypothesis, both DID parameters in a given regression equal zero (Wooldridge, 2000; 414-419). New York's business tax reforms would be found to have had no effect on unemployment, relative to Pennsylvania, if the null for both DID coefficients are not rejected. If DID $_{S U}$ coefficient is negative and statistically significant, START-UP NY enterprise zones are working as designed; they are associated with lower unemployment than the other counties in New York and Pennsylvania. If the DID $_{N Y}$ coefficient is negative and statistically significant, the corporate tax cut is reducing unemployment relative to Pennsylvania. It could also be the case that the pair of DID estimates are positive and statistically significant. This would be the result of the business tax reforms pulling displaced workers back into the labor force as the reforms encourage startup incubation and firm expansions within the state.

The nature of the county specific effects must also be addressed econometrically. If the county specific effects take mean values other than zero, the county effects may be modeled using a series of binary variables, each of which identifies a specific county, yielding the traditional fixed effects estimator. If these effects are most appropriately modeled as having means of zero, the random effects estimator is a more efficient estimation technique (Wooldridge, 2000; 441-450). Given that one of the regressors is whether or not a county is located in New York, it is tautologically the case that the regressors are correlated with the county-specific effects. Thus, the random effects model is inappropriate, and the fixed effect 
estimator is used. ${ }^{9}$ All fixed effect models are estimated using clustered robust standard errors (Duflo, Mullainathan, and Bertrand, 2004).

The overall significance of each regression is assessed using standard F-tests for OLS and fixed effect models. T-tests are used to evaluate hypothesis tests on individual parameter estimates. All tests on individual parameter estimates are conducted using two-sided confidence intervals and a five percent significant level. Joint (i.e., F) tests are conducted using 1-sided confidence intervals and five percent significance levels. Within the fixed effect model, heteroscedasticity and autocorrelation are also of concern. The Breusch-Pagan test is used to test for heteroscedasticity (Greene, 200; pp. 509-510), while the Breusch-Godfrey test is used to assess the presence of autocorrelation (Greene, 2000; pp. 540-542).

\section{Data}

Nearly all of the data for this study are drawn from the Federal Reserve Economic Database (FRED). County level unemployment rates (urate) are collected for the years 2014-2017. To ensure a set of exogenous (i.e., pre-determined) set of covariates, a number of variables were collected on county-level characteristics over the years preceding the study's time frame. More specifically, to measure the available pool of qualified workers, we collected data on the percentage of residents 25 years of age or older with an associate's degree (L3_as) two years prior to the study period (i.e., 2011-2014). ${ }^{10}$

To control for household income and business conditions within a county, we collected data on real median household income two years prior to the study period (2011-2014; $\left.L 3 \_M H I\right)$ as well as small business ownership rates two years prior to the study period (20112014; L3_sbiz). To account for socio-demographics and income disparities, we collected county-level data on the white to non-white racial dissimilarity index for the years 2011-2014 (L3_race), homeownership rate for the years 2011-2014 (L3_hown), and income inequality for the years 2011-2014 (L3_incineq). ${ }^{11}$

Since START-UP NY may induce county and state migration as workers vie for the employment expansion that New York expects from the program, we control for this effect by including a binary variable (posNmig) that is equal to one if a county had net positive

\footnotetext{
${ }^{9}$ We note in passing that we also estimated our main regressions using the random effects model and empirically evaluated the fixed and random effects estimates using the Hausman test (Greene, 2000; pp 576-577). We thank an anonymous reviewer for pointing out the theoretical rationale for using the fixed effect model.

${ }^{10}$ Values were imputed using multiple regression and for one Pennsylvania county.

${ }^{11}$ Although real gross state domestic product was chosen to be included as a covariate to control for differences in the two state's economies, these and other state-level variables were dropped because state-level variables vary over time but not across the 60 plus counties of each state during a given year.
} 
migration but equal to zero if otherwise. Since people may need to sell homes, wait for apartment leases to expire, wait for their children's schools' summer breaks to commence, or exhaust unemployment insurance benefits, we expect this effect to be delayed.

Given that START-UP NY's primary function is to incentivize high technology firms to incubate or expand their operations in New York State, we included a variable that captures the initial state of entrepreneurship in the Professional, Scientific, and Technical Services (NAICS 54) industry in all counties just prior to the implementation of START-UP NY. ${ }^{12}$ This variable (pstGrowth14) equals the 2013-2014 annual growth rate of firms that operate under this industry classification. It was computed using data from United States Census Bureau $^{13}$ and varies by county but not time. Future county unemployment rates would respond much differently to START-UP NY in counties that had low and high levels of entrepreneurship in this industry.

\section{Results}

Table 1 provides descriptive statistics for each of our study variables, disaggregated by state and county. By examining mean differences between New York and Pennsylvania counties, it is possible to identify similarities and differences between the two states. The median values for virtually all county variables are roughly equal to their corresponding means; hence, the discussion focuses primarily on the sample means. In addition, the descriptive statics reported in the table were averaged over the period of study, from 2014 to 2017. The average county in New York exhibits a lower unemployment rate $(5.58 \%)$ than the average Pennsylvania county (5.80\%). New York's associate's degree rate (36.4 percent) is slightly higher than Pennsylvania's rate (28.49 percent). At the county level, real median household income (51,235 2017-dollars) in Pennsylvania is slightly less than it is New York $(55,732$ 2017-dollars). The small business rate and racial diversity are very similar across states. The average county homeownership rate is about five percentage points higher in Pennsylvania (76.69 percent) than it is in New York (71.47 percent). If this is partly due to New York's higher cost of living, this variable helps control for cost of living differences that exist between the two states. Income inequality is 1.44 percentage points higher in New York (12.98) than it is in Pennsylvania (11.54). The economic growth rate is higher in Pennsylvania (1.62\%) than it is in New York (1.28\%). Professional, Scientific, and Technical Services entrepreneurial activity was lower in New York counties than in Pennsylvania. More specifically, from 2013 to 2014, firm growth rate for this industry was $-0.91 \%$ in New York

\footnotetext{
${ }^{12}$ We also considered including the growth rate of manufacturing firms (NAICS 31-33) because enhancing manufacturing within NY is also a goal of START-UP NY. However, the variable was highly insignificant in all models we estimated. As such, we sided with parsimonious modeling.

${ }^{13}$ These data are available at the U.S. Department of the Census' website (2014) for all US counties.
} 
Review of Economic Analysis 10 (2018) 245-266

Table 1: Descriptive Statistics

\begin{tabular}{|c|c|c|c|c|c|c|c|c|}
\hline & \multicolumn{4}{|c|}{ NY Counties $(\mathrm{N}=62, \mathrm{~T}=4)$} & \multicolumn{4}{|c|}{ PA Counties $(\mathrm{N}=67, \mathrm{~T}=4)$} \\
\hline & Mean & $\mathrm{sd}$ & $\min$ & Max & Mean & $\mathrm{sd}$ & $\min$ & $\max$ \\
\hline Urate & 5.58 & 1.05 & 3.68 & 10.17 & 5.80 & 1.05 & 3.61 & 8.41 \\
\hline L3_as & 36.4 & 8.00 & 23.50 & 63.00 & 28.49 & 7.93 & 13.30 & 54.7 \\
\hline L3_hown & 71.47 & 12.29 & 20.27 & 86.99 & 76.69 & 4.78 & 56.21 & 86.97 \\
\hline L3 incineq & 12.98 & 4.38 & 8.08 & 40.71 & 11.54 & 2.12 & 7.75 & 22.02 \\
\hline L3_MHI & 55732 & 13292 & 34678 & 101714 & 51235 & 9575.7 & 35769 & 88576 \\
\hline L3 posNmig & 0.45 & 0.50 & 0 & 1 & 0.51 & 0.50 & 0 & 1 \\
\hline L3_race & 40.89 & 13.08 & 12.15 & 74.57 & 40.75 & 13.01 & 2.77 & 76.96 \\
\hline L3_sbiz & 27.61 & 7.88 & 15.70 & 67.05 & 27.05 & 3.71 & 18.73 & 37.87 \\
\hline L3_sphwkids & 33.15 & 7.04 & 16.04 & 63.24 & 30.63 & 5.80 & 16.97 & 55.32 \\
\hline L3_growth & 1.28 & 1.31 & -0.27 & 3.15 & 1.62 & 0.21 & 1.3 & 1.89 \\
\hline pstGrowth14 & -0.91 & 4.23 & -15.38 & 6.90 & -0.15 & 4.20 & -7.69 & 20 \\
\hline SU & 0.74 & 0.44 & 0 & 1 & & & & \\
\hline
\end{tabular}

Source: For all data but $S U$ and pstGrowth14 are from the Federal Reserve Economic Database, $S U$ was defined using public START-UP NY data, and pstGrowth14 is from the US Census Bureau.

versus $-0.15 \%$ in Pennsylvania. Finally, more Pennsylvania counties experienced higher positive net migration (51\%) than their New York counterparts (45\%).

Table 2 reports the descriptive statistics that are disaggregated by year. From 2014 to 2015, county unemployment fell 0.69 percentage points in Pennsylvania, but fell 0.80 percentage points in New York Counties. The difference in these values is the raw initialeffect DID estimate (-0.11) as characterized by equation (1). From 2015 to 2016, as the county unemployment rose 0.31 percentage points in Pennsylvania, it fell 0.56 percentage points in New York. The difference in these values is the raw intermediate-effect DID estimate (-0.87), again, as characterized by equation (1). From 2016 to 2017, county unemployment fell 0.62 percentage points in Pennsylvania, but increased 0.05 percentage points in New York. The difference in these differences is the raw tertiary-effect DID estimate (0.57), as characterized by equation (1). Although the DID estimate is insignificant for the initial-effect model, it is significant for the intermediate- and tertiary-effect estimates. ${ }^{14}$ Thus, preliminary results suggest that, while both states had similar declines in county unemployment in the year New York State reformed its corporate tax system, the

\footnotetext{
${ }^{14}$ Ordinary Least Squares (OLS) was used to estimates the raw DID estimates computed in Table 2. In these regressions, county unemployment rate was regressed on treatment variable NY, post-treatment dummy $Y E A R$, and the interaction of these two dummy variables $(N Y \times Y E A R)$. The standard errors for the raw initial-, intermediate-, and tertiary-effect DID estimates are $0.242,0.233$, and 0.226 , respectively.
} 
unemployment rate decreased more in New York than it did in Pennsylvania during the reform's second year, but increased more in New York than it did in Pennsylvania during the reform's third year. Thus, it appears that the changes in New York's corporate tax policy has a seemingly ambiguous effect on New York unemployment.

We posit three explanations for the unexpected positive raw tertiary-effect DID estimate: (a) either the relevant classical statistical assumptions do not hold, which would invalidate the OLS results used to compute the test statistics, (b) these assumptions are satisfied, and a greater number of New York residents entered the labor force during 2016 than did during 2015, or (c) firms that were launched in 2014 and 2015 with the help of START-UP NY may have shuttered during 2016. If one or both of the latter two scenarios are true, then we should expect the unemployment rate to rise sharply from 2016 to 2017. Thus, for the initial period only, the null hypothesis, New York State's business tax reforms have had no effect on unemployment, is not rejected. This result also provides prima fascia evidence (but not proof) that the common trend assumption is appropriate. It remains to be seen whether controlling for other important socio-cultural and economic factors alters these preliminary findings.

Table 2 also provides descriptive statistics for the study's control variables, disaggregated by state and year. Interestingly, while mean differences in the control variables do exist across New York and Pennsylvania counties, the descriptive statistics for a particular state are relatively stable over the length of the panel. For example, the home ownership rate in New York was approximately 71.9 in 2014, 71.7 in 2015, 71.3 in 2016, and 71.0 in 2017. Concomitantly, homeownership rates in Pennsylvania during the same time frame were 77.3, 76.9, 76.5, and 76.2, respectively. An examination of the descriptive statistics for the remaining variables in Table 2 yield similar trends; there are mean differences across states, but for a specific state, the descriptive statistics are surprisingly stable over the length of the panel.

Table 3 contains the DID estimates for equations (4) and (5). For simplicity, the results in Table 3 are evaluated across specifications to evaluate the study's primary null hypothesis concerning the effectiveness of New York State's recent corporate tax reforms. Once the null hypothesis has been evaluated, the remaining control variables in the final specification (equation (5)) are examined to determine how the other control variables impact county level unemployment rates.

The estimates for equation (4) are summarized in columns (1) and (2) of Table 3. The estimates in the first column were estimated using OLS (which are presented solely as a relative baseline against which to evaluate naïve DID results presented in Table 2 and the fixed effect estimates presented in Table 3), while those in the second column are fixed 
effects estimates with clustered robust standard errors. ${ }^{15}$ The adjusted R-square in the OLS estimation is 0.62 , which indicates that the model fits the data with a reasonable level of accuracy and precision. The OLS and fixed effects 2015 DID estimates in Table 3 (-0.117 and $-0.099)$ are roughly equal to the corresponding raw 2015 DID estimate $(-0.11)$ computed using the urate means reported in the 2014 and 2015 panels of Table 2. The OLS and fixed effects 2016 DID estimates in Table $3(-1.023$ and -0.966$)$ are slightly more negative than the corresponding raw DID estimate $(-0.87)$ from Table 2 . The raw estimate of the 2017 DID estimator (0.57) has the opposite sign of its counterpart in Table 3, the OLS and fixed effects 2017 DID estimates (-0.427 and -0.369). Like the raw estimates of the DID estimator, only the intermediate and tertiary OLS and fixed effects DID estimates are statistically significant.

Table 2: Disaggregated Descriptive Statistics

\begin{tabular}{|c|c|c|c|c|c|c|c|c|}
\hline & \multicolumn{4}{|c|}{ PA Counties $(\mathrm{N}=67)$} & \multicolumn{4}{|c|}{ NY Counties $(\mathrm{N}=62)$} \\
\hline & mean & $\mathrm{sd}$ & $\min$ & $\max$ & mean & $\mathrm{sd}$ & $\min$ & $\max$ \\
\hline \multicolumn{9}{|l|}{2014} \\
\hline$\overline{\text { urate }}$ & 6.32 & 1.03 & 4.29 & 8.41 & 6.47 & 1.05 & 4.44 & 10.17 \\
\hline L3_as & 27.74 & 7.94 & 13.3 & 54.1 & 35.79 & 7.97 & 23.8 & 61.4 \\
\hline L3_hown & 77.29 & 4.75 & 58.52 & 86.49 & 71.9 & 12.34 & 21.25 & 86.99 \\
\hline L3_incineq & 11.3 & 2.02 & 7.75 & 20.68 & 12.66 & 4.34 & 8.08 & 40.01 \\
\hline L3_MHI & 50749.97 & 9551.41 & 35769.05 & 86567.8 & 55649.56 & 13287.9 & 34990.56 & 99256.6 \\
\hline L3_posNmig & 0.6 & 0.49 & 0 & 1 & 0.5 & 0.5 & 0 & 1 \\
\hline L3_race & 40.96 & 13.99 & 7.94 & 76.96 & 41.56 & 13.04 & 13.83 & 74.57 \\
\hline L3_sbiz & 26.91 & 3.69 & 19.18 & 34.82 & 27.45 & 7.82 & 15.7 & 66.98 \\
\hline L3_sphwkids & 29.8 & 5.55 & 16.97 & 54.74 & 32.45 & 7.21 & 16.04 & 63.13 \\
\hline $\begin{array}{l}\text { pstGrowth14 } \\
\underline{2015}\end{array}$ & -0.15 & 4.22 & -7.69 & 20 & -0.91 & 4.26 & -15.38 & 6.9 \\
\hline$\overline{\text { urate }}$ & 5.63 & 0.92 & 3.82 & 7.88 & 5.67 & 0.88 & 4.11 & 8.06 \\
\hline L3_as & 28.2 & 7.93 & 14.1 & 54.3 & 36.1 & 8.12 & 23.5 & 61.8 \\
\hline L3_hown & 76.86 & 4.83 & 57.59 & 86.77 & 71.65 & 12.39 & 20.88 & 86.94 \\
\hline L3_incineq & 11.46 & 2.1 & 7.83 & 21.25 & 12.83 & 4.4 & 8.54 & 40.11 \\
\hline L3_MHI & 50994.48 & 9592.84 & 37006.31 & 87954.11 & 55798.55 & 13218.24 & 34677.74 & 99147.84 \\
\hline L3_posNmig & 0.55 & 0.5 & 0 & 1 & 0.45 & 0.5 & 0 & 1 \\
\hline L3_race & 41.56 & 12.41 & 11.57 & 69.92 & 41.18 & 13.19 & 13.28 & 70.75 \\
\hline L3_sbiz & 27.03 & 3.69 & 19.1 & 36.29 & 27.57 & 7.88 & 15.91 & 66.98 \\
\hline L3_sphwkids & 30.43 & 5.68 & 17.48 & 55.32 & 33.02 & 7.17 & 16.85 & 63.21 \\
\hline pstGrowth14 & -0.15 & 4.22 & -7.69 & 20 & -0.91 & 4.26 & -15.38 & 6.9 \\
\hline
\end{tabular}

${ }^{15}$ At 5 percent significance, the Hausman test indicated that the fixed effects model is more appropriate than the random effects model, and the Breusch-Pagan test for heteroscedasticity and the BreuschGodfrey test for autocorrelation indicated that the errors of the fixed-effects models are heteroscedastic and serially correlated. 
SNARR, SNARR, FRIESNER New York Supply-Side Experiment

Table 2 continued

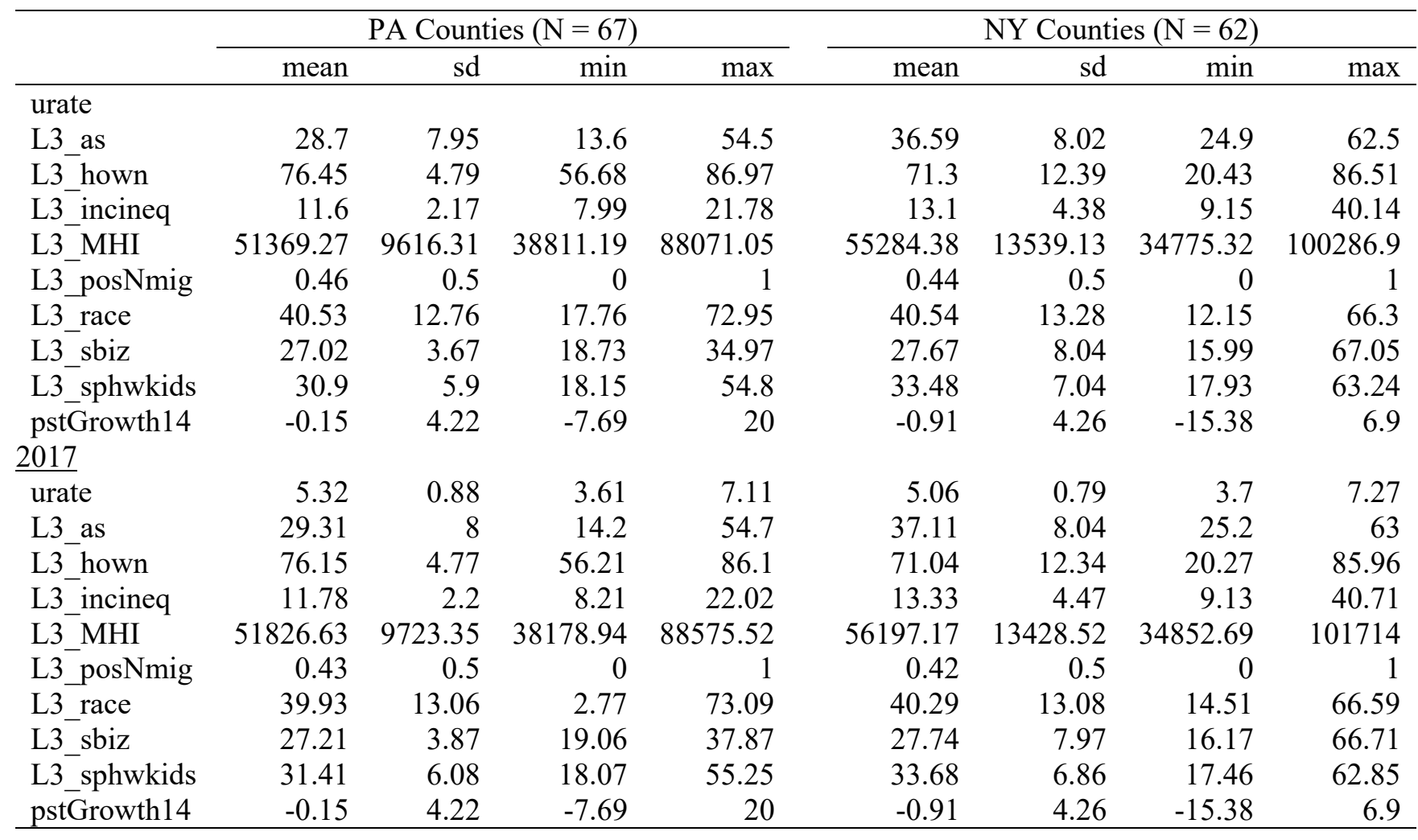

Source: For all data but SU and pstGrowth14 are from the Federal Reserve Economic Database, SU was defined using public START-UP NY data, and pstGrowth14 is from the US Census Bureau

In columns (1) and (2), the intermediate-effect is about 0.9 percentage points higher than the initial-effect, while the tertiary-effect is 0.6 percentage points lower than the intermediateeffect. These results suggest that New York State's business tax reforms have a diminishing effect on county unemployment. However, it is unclear how much of this effect is due to START-UP NY or to the 2016 cut in the New York corporate tax rate.

The estimates for equation (5) are summarized in columns (3) and (4) of Table 3. Like above, those on the right are OLS estimates and those on the left are fixed effects estimates with clustered robust standard errors. This specification allows us to disentangle the effects of corporate tax rate reductions and START-UP NY because both sets of DID estimators $\left(\right.$ DID $_{\mathrm{NY}}$ and DID $\left._{\mathrm{SU}}\right)$ are included in the model. The DID $\mathrm{SU}_{\mathrm{SU}}$ estimates are all insignificant. Thus, the hypothesis that START-UP NY has no effect on unemployment is not rejected. All but one of the $\operatorname{DID}_{\mathrm{NY}}$ estimates are significant, which means we reject the hypothesis that 
Review of Economic Analysis 10 (2018) 245-266

Table 3: Regression Results

\begin{tabular}{|c|c|c|c|c|}
\hline & (1) & (2) & (3) & $(4)$ \\
\hline NY & $\begin{array}{l}0.652^{* * *} \\
(0.140)\end{array}$ & & $\begin{array}{c}0.598^{* *} \\
(0.185)\end{array}$ & \\
\hline SU & $\begin{array}{l}-0.065 \\
(0.101)\end{array}$ & & $\begin{array}{c}0.008 \\
(0.193)\end{array}$ & \\
\hline Y15 & $\begin{array}{l}-0.686^{* * *} \\
(0.112)\end{array}$ & $\begin{array}{l}-0.712^{* * *} \\
(0.045)\end{array}$ & $\begin{array}{l}-0.686^{* * *} \\
(0.113)\end{array}$ & $\begin{array}{l}-0.712^{* * *} \\
(0.045)\end{array}$ \\
\hline Y15xNY & $\begin{array}{c}-0.117 \\
(0.162)\end{array}$ & $\begin{array}{c}-0.099 \\
(0.060)\end{array}$ & $\begin{array}{c}-0.051 \\
(0.257)\end{array}$ & $\begin{array}{l}-0.084 \\
(0.082)\end{array}$ \\
\hline Y15xSU & & & $\begin{array}{c}-0.089 \\
(0.268)\end{array}$ & $\begin{array}{c}-0.019 \\
(0.090)\end{array}$ \\
\hline Y16 & $\begin{array}{l}-0.359^{* *} \\
(0.113)\end{array}$ & $\begin{array}{l}-0.417^{* * *} \\
(0.098)\end{array}$ & $\begin{array}{l}-0.359^{* *} \\
(0.113)^{* * *}\end{array}$ & $\begin{array}{l}-0.414^{* * *} \\
(0.098)\end{array}$ \\
\hline Y16xNY & $\begin{array}{l}-1.023^{* * *} \\
(0.162)\end{array}$ & $\begin{array}{l}-0.966^{* * *} \\
(0.099)\end{array}$ & $\begin{array}{l}-0.990^{* * *} \\
(0.257)\end{array}$ & $\begin{array}{l}-0.941^{* * *} \\
(0.134)\end{array}$ \\
\hline Y16xSU & & & $\begin{array}{l}-0.045 \\
(0.268)\end{array}$ & $\begin{array}{l}-0.033 \\
(0.126)\end{array}$ \\
\hline Y17 & $\begin{array}{l}-0.958^{* * *} \\
(0.114)\end{array}$ & $\begin{array}{l}-1.072^{* * *} \\
(0.095)\end{array}$ & $\begin{array}{l}-0.958^{* * *} \\
(0.114)\end{array}$ & $\begin{array}{l}-1.067^{* * *} \\
(0.095)\end{array}$ \\
\hline Y17xNY & $\begin{array}{l}-0.427^{* *} \\
(0.162)\end{array}$ & $\begin{array}{l}-0.369^{* * *} \\
(0.099)\end{array}$ & $\begin{array}{l}-0.310 \\
(0.257)\end{array}$ & $\begin{array}{l}-0.254^{*} \\
(0.108)\end{array}$ \\
\hline Y17xSU & & & $\begin{array}{l}-0.158 \\
(0.268)_{* * *}\end{array}$ & $\begin{array}{l}-0.155 \\
(0.138)\end{array}$ \\
\hline L3_as & $\begin{array}{l}-0.051^{* * *} \\
(0.007)\end{array}$ & $\begin{array}{l}0.094^{* *} \\
(0.035)\end{array}$ & $\begin{array}{l}-0.051^{* * *} \\
(0.007)\end{array}$ & $\begin{array}{c}0.094^{* *} \\
(0.035)\end{array}$ \\
\hline L3_hown & $\begin{array}{l}0.017^{* *} \\
(0.006)_{* * *}\end{array}$ & $\begin{array}{l}0.084^{* *} \\
(0.027)\end{array}$ & $\begin{array}{l}0.017^{* *} \\
(0.006)_{* *}\end{array}$ & $\begin{array}{l}0.085^{* *} \\
(0.028)\end{array}$ \\
\hline L3_incineq & $\begin{array}{l}0.061^{* * *} \\
(0.019)^{* * *}\end{array}$ & $\begin{array}{l}-0.074 \\
(0.059)\end{array}$ & $\begin{array}{l}0.061^{* *} \\
(0.019)^{* * *}\end{array}$ & $\begin{array}{l}-0.075 \\
(0.060)\end{array}$ \\
\hline L3_lnMHI & $\begin{array}{l}-1.638^{* * *} \\
(0.293)\end{array}$ & $\begin{array}{c}0.002 \\
(0.465)\end{array}$ & $\begin{array}{l}-1.642^{* * *} \\
(0.294)\end{array}$ & $\begin{array}{l}-0.022 \\
(0.464)\end{array}$ \\
\hline L3_posNmig & $\begin{array}{l}-0.145^{*} \\
(0.061)\end{array}$ & $\begin{array}{l}-0.082 \\
(0.071)\end{array}$ & $\begin{array}{l}-0.146^{*} \\
(0.061)\end{array}$ & $\begin{array}{l}-0.083 \\
(0.071)\end{array}$ \\
\hline L3_race & $\begin{array}{c}0.004 \\
(0.003)\end{array}$ & $\begin{array}{c}0.009 \\
(0.006)\end{array}$ & $\begin{array}{c}0.004 \\
(0.003)\end{array}$ & $\begin{array}{c}0.010 \\
(0.006)\end{array}$ \\
\hline L3_sbiz & $\begin{array}{c}0.014^{*} \\
(0.006)\end{array}$ & $\begin{array}{c}0.016 \\
(0.037)\end{array}$ & $\begin{array}{c}0.014^{*} \\
(0.006)\end{array}$ & $\begin{array}{c}0.015 \\
(0.037)\end{array}$ \\
\hline L3_sphwkids & $\begin{array}{c}0.021^{* *} \\
(0.007)\end{array}$ & $\begin{array}{c}0.026^{*} \\
(0.010)\end{array}$ & $\begin{array}{c}0.021^{* *} \\
(0.007)\end{array}$ & $\begin{array}{c}0.026^{*} \\
(0.010)\end{array}$ \\
\hline pstGrowth14 & $\begin{array}{l}-0.021^{* *} \\
(0.007)\end{array}$ & & $\begin{array}{l}-0.021^{* *} \\
(0.007)\end{array}$ & \\
\hline$N_{2}$ & 516 & 516 & 516 & 516 \\
\hline$R^{2}$ & 0.63 & 0.79 & 0.63 & 0.79 \\
\hline adj. $R^{2}$ & 0.62 & 0.78 & 0.62 & 0.78 \\
\hline
\end{tabular}

Standard errors in parentheses 
New York State's corporate tax rate reduction had no effect on unemployment. The significant DID $_{\mathrm{NY}}$ estimates imply that New York's lower corporate tax rate is associated with 0.94 percentage point decline in unemployment (relative to Pennsylvania) during the first year of the lower corporate tax rate and a 0.25 percentage point decline in its second year. The results also indicate that, over the period study, county unemployment is 0.6 percentage points higher in New York than it is in Pennsylvania, and that STARTUP-NY counties do not have lower unemployment than the other counties in the study.

The DID estimates reported in column (4) of Table 3 are graphically illustrated in Figure 2. The gray curve in this figure gives the tangled effects of START-UP NY and New York's lower corporate tax rates, the set of DID coefficients reported in the first column of Table 3. The black smooth and dashed curves illustrate how the policies separately affect New York county employment. The dashed line maps out the DIDSU estimates. It shows that STARTUP NY may have, at best, a very slight but increasing effect on employment conditions in the average New York County (relative to Pennsylvania). This small, increasing positive insignificant effect could be a result of startups incubated on START-UP NY campuses being small employers. It could be the case that, over a longer period of study, the employment effects could be much larger and significant. The solid black curve maps out the DIDNY estimates. It indicates a substantial improvement to New York employment conditions in the year the New York corporate tax rate was lowered from $7.1 \%$ to $6.5 \%$ in 2016 . It also shows that employment effect was much less in the second year. The decline in the positive employment effect that is associated New York's lower corporate tax rate is perhaps due to

Figure 2: The START-UP NY Employment Effect

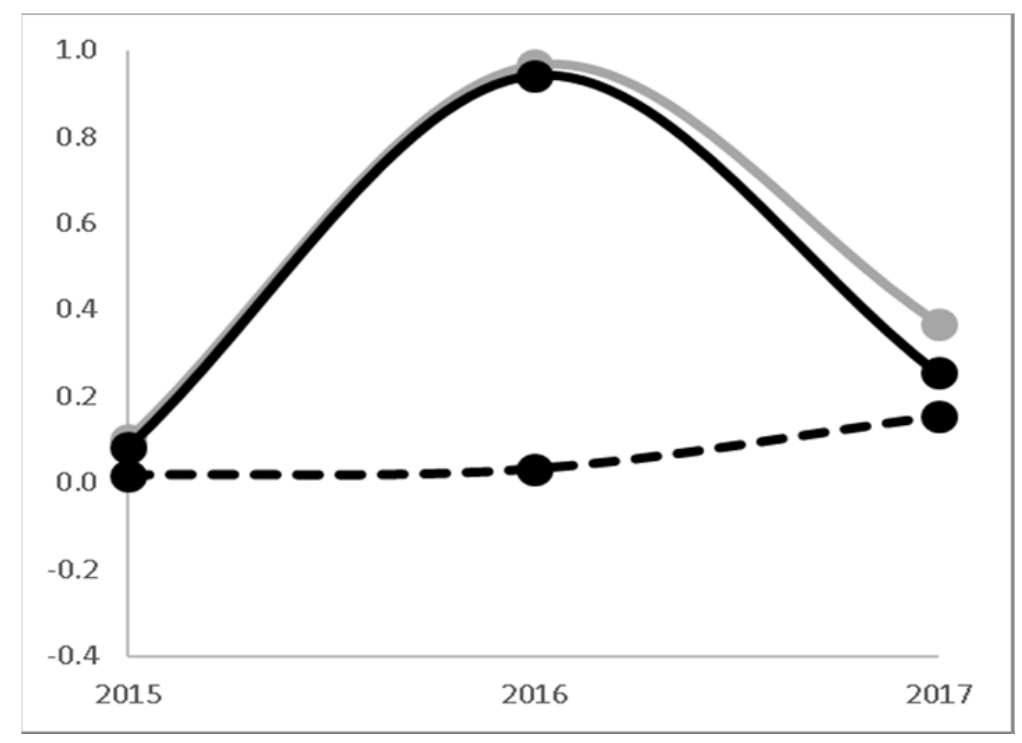


many more displaced workers looking for work in 2017 than did in 2016. For the same employment growth, this would result in the labor force growing faster in 2017 than it did in 2016.

For the remainder of this section, particular attention is paid to the final four-period model reported in column (4) of Table 3. Many of the reported coefficients not yet discussed are statistically significant at the 5 percent level or better. The coefficient estimates for the year dummies in the final column shows how the business cycle affects unemployment. Unemployment improved by 0.71 percentage points in 2015, 0.41 percentage points in 2016, and 1.1 percentage points in 2017. The education coefficient implies that unemployment increases in the share of county residents with at least an associate degree. This perhaps results from the size of the labor market swellings as more and more people graduate with two-year college degrees. The positive homeownership coefficient suggests that unemployment is higher in counties with high homeownership, because perhaps owning a home acts like an anchor that inhibits people from migrating away from an economically depressed county. The positive and significant single-parent with children coefficient suggests that unemployment rises modestly as the rate of single-parents raising children rises within a county.

\section{Conclusions}

The critics of supply-side policies, like the business tax reforms that New York initiated in 2014, are numerous, and hail from both conservative and liberal political ideologies. For example, Mikkelson (2014) — a noted political liberal—wrote: “The supply-side economic theories that underlie [Governor] Cuomo's tax cut proposals have had fat cats laughing all the way to the bank since long before Arthur Laffer devised his dubious curve, despite the fact that these theories have been widely discredited." Concomitantly, Iain Murray, a conservative and the Vice President for Strategy at the Competitive Enterprise Institute in Washington, said "[the tax-free] zones appear to be the latest in a series of variations on President Reagan's enterprise zones, which had some success in the 1980s. Unfortunately, and this was the case with Reagan's version, too, they don't really go far enough to foster a real free-market revival" (Chumley 2014). Given that New York State's 2014 supply-side experiment involved tax-free enterprise zones and lower state-wide corporate tax cuts, an evaluation of the effectiveness of both reforms is warranted.

Preliminary descriptive findings suggested that New York's recent business tax reforms reduced unemployment in the region between 2015 and 2016 and between 2016 and 2017. Our four-period DID estimates, which disentangled the effects of these two business tax reforms, suggest that START-UP NY has had only a very slight, but increasing, effect on 
employment in the region. This small, increasing positive insignificant effect is perhaps a result of the startups that were incubated in the START-UP NY enterprise zones were simply small employers who, over a longer period of study, might become larger employers. The disentangled results also indicate that New York lowering its corporate tax rates from in 2016 is the primary driver of the improving New York labor market. In 2016, the lower corporate tax rate is associated with a 0.9 percentage point reduction in unemployment. For a labor market of roughly 10 million workers, that equates to 90,000 fewer unemployed workers in the state. The following year, the effect is roughly 27 percent of what it was the previous year, which amounts to approximately 25,000 fewer unemployed workers.

These results contain several policy implications. First, START-UP NY effects are difficult to measure with current data. The program is incubating firms that hire residents, but, given that these firms are still in their infancy, the employment effect is not yet measurable at the county level. Second, the lower corporate tax rate appears to be an effective economic development policy tool over a short time frame. Third, the effectiveness of the lower corporate tax rate's effect diminished in the second year, suggesting that doing so may not be an effective long run economic development policy.

If one interprets the positive effects of New York's business tax reforms as a success over a short time, there is an additional caveat that must be considered. The percentage reduction in the New York unemployment rate that is attributed to these changes is measured relative to Pennsylvania. If these reforms incubated firms or existing firms expanded in New York are firms that would have done so in Pennsylvania or other states, then New York's business tax reforms are simply shifting the location of where firms choose to initiate or expand their operations; the Wilson (2009) conclusion. While this may be deemed a success from the perspective of a single state (New York), it would be considered an ineffective policy from a national perspective. Further research is needed to address this issue.

While our results provide an interesting evaluation of New York's recent business tax reforms, they are subject to several other limitations, which must be addressed in future research. The biggest concern for county-level studies that use the unemployment rate to evaluate policy is that this measure represents the economic prosperity of the county where people live, not where they work. If unemployed workers living in non-START-UP NY counties are the ones hired by START-UP NY participants, then the $\operatorname{DID}_{N Y}$ and DID $_{\mathrm{SU}}$ estimates would not represent the disentangled effects of the reforms. With that said, we suspect that this is not the case here. As of October 2016, there were only about 200 participants in the program that had committed to creating around 4500 new jobs (Cuomo, 
2016). This is a far cry from the 90,000 fewer unemployed workers we estimated for 2016 and the 25,000 for 2017 .

Second, our analysis uses data covering the first few years of START-UP NY. It is possible that, over time, the program may become disproportionately more or less successful. This is especially true given that our results identified a slight increasing effect. Over time, changes may alter the program's guidelines, and/or the means by which the existing program guidelines are implemented, either of which may impact the program's effectiveness. Further research that replicates our study using a longer time period would provide greater insights into the program's effectiveness.

\section{References}

Bennett, Robert (1990), The Incentives to Capital in the UK Enterprise Zones, Applied Economics, 22(3), 387-402.

Bruns, Adam (2013), No Taxes Means No Taxes, Site Selection Magazine, http://siteselection.com/issues/2013/nov/upstate-ny.cfm.

Card, David (1992), Do Minimum Wages Reduce Employment? A Case Study of California, 1987-1989, Industrial and Labor Relations Review, 46(1), 38-54.

Card, David and Alan Krueger (1994) Minimum Wages and Employment: A Case Study of the Fast-Food Industry in New Jersey and Pennsylvania, The American Economic Review, 84(4), 772-793.

Chumley, Cheryl (2014), Critics: Cuomo's 'Tax-Free' Plan for NY Is Not So Tax-Free, Newsmax, $\quad$ www.newsmax.com/Newsfront/Cuomo-New-York-tax-free/2014/02/04/id/ 550910/.

Columbia University Mailman School of Public Health (2018), Difference-in-Difference Estimation, https://www.mailman.columbia.edu/research/population-health-methods/ difference-difference-estimation.

Couch, Jim, Keith Atkinson, and Lewis Smith (2005), The Impact of Enterprise Zones on Job Creation in Mississippi, Contemporary Economic Policy, 23(2), 255-260.

Couch, Jim and J. Douglas Barrett (2004), Alabama's Enterprise Zones: Designed to Aid the Needy? Public Finance Review, 32(1), 65-81.

Cuomo, Andrew (2016), Governor Cuomo Announces 39 More Companies Join Start-Up NY and Commit to 817 New Jobs, www.governor.ny.gov/news/governor-cuomo-announces39-more-companies-join-start-ny-and-commit-817-new-jobs. 
SNARR, SNARR, FRIESNER New York Supply-Side Experiment

Czarnitzki, Dirk, Petr Hanel, and Julio Miguel Rosa (2011), Evaluating the Impact of R\&D Tax Credits on Innovation: A Microeconometric Study on Canadian Firms, Research Policy, 40(2), 217-229.

Duflo, Esther, Sendhil Mullainathan, and Marianne Bertrand (2004), How Much Should We Trust Difference in Differences Estimates? Quarterly Journal of Economics, 119 (1), 249275.

Erickson, Rodney and Susan Friedman (1989), Enterprise Zones: An Evaluation of State Government Policies. Washington, DC: U.S. Department of Commerce.

Erickson, Rodney and Susan Friedman (1990), Enterprise Zones: 1. Investment and Job Creation of State Government Programs in the United States of America, Environment and Planning C: Politics and Space, 8(3), 251-267.

Gormley, Michael (2015), Observers question benefits to state from tax break programs for businesses, Newsday, www.newsday.com/business/observers-question-benefits-to-statefrom-tax-break-programs-for-businesses-1.9891536.

Greene, William (2000), Econometric Analysis, $4^{\text {th }}$ Ed. Upper Saddle River, NJ: Prentice Hall.

Henchman, Joseph (2014), New York Corporate Tax Overhaul Broadens Bases, Lowers Rates, and Reduces Complexity, Tax Foundation Special Report, https://files.taxfoundation.org/legacy/docs/SR217.pdf.

Mikkelson, Jeffrey (2014), State of the Estate: Cuomo's Tax Giveaway to the Rich, Truthout, www.truth-out.org/opinion/item/21408-state-of-the-estate-cuomos-tax-giveaway-to-therich.

Rocha, Hector (2004), Entrepreneurship and Development: The Role of Clusters, Small Business Economics, 23, 363-400.

Rubin, Barry and Margaret Wilder (1989), Urban Enterprise Zones: Employment Impacts and Fiscal Incentives, Journal of the American Planning Association, 55(4), 418-431.

Rubin, Marilyn and Donald Boyd (2013), New York State Business Tax Credits: Analysis and Evaluation, New York State Tax Reform and Fairness Commission, http://www.pjsc.com/news/media/2013-11-13-Tax_Incentive_Study_Final.pdf.

Tax Foundation (2017), How Does your State Compare? Facts \& Figures 2017, https://files.taxfoundation.org/20170710170127/TF-Facts-Figures-2017-7-10-2017.pdf.

Thurik, Roy and Sander Wennekers (2004), Entrepreneurship, Small Business and Economic Growth, Journal of Small Business and Enterprise Development, 11(1), 140-149.

United States Bureau of Transportation Statistics (2017), Maritime and Inland Waterways Featured Visualization: Top 25 Water Ports by Container Cargo: 2015, https://www.bts.gov/topics/maritime-and-inland-waterways. 
United States Department of the Census (2014), 2013-2014 SUSB Employment Change Data Tables, www.census.gov/data/tables/2014/econ/susb/2014-susb-employment.html.

Wilson, Daniel J. (2009), Beggar Thy Neighbor? The In-State, Out-of-State, and Aggregate Effects of R\&D Tax Credits, The Review of Economics and Statistics, 91(2), 431-436.

Winegarden, Wayne (2015), The 50-State Small Business Regulation Index, Pacific Research Institute Report, $\quad$ http://danabeigeldesign.com/wp-content/uploads/2016/02/ SmBusinessIndex UpdatedVersion2 web.pdf.

Wooldridge, Jeffrey (2000), Introductory Econometrics: A Modern Approach. Cincinnati, $\mathrm{OH}$ : South-Western Publishing. 